\title{
Großes Jubiläumsfest in Münster
}

\author{
Mit mehr als 40000 Gästen feierte Brillux sein 125-jähriges Jubiläum in Münster. \\ Drei Tage lang zeigte der Lack- und Farbenhersteller aktuelle Trends und Neuentwicklungen \\ auf über 6000 Quadratmetern Ausstellungsfläche.
}

V om 27. bis 29. Juni 2014 öffnete Brillux die Tore seiner Zentrale in Münster: Mit Betriebsbesichtigungen und einer Erlebnisausstellung feierte das Unternehmen sein 125-jähriges Jubiläum mit Kunden und Partnern. Mehr als 40000 Gäste, darunter Maler, Lackierer, Stuckateure, Architekten, Bauplaner und Fachleute der Wohnungswirtschaft, aus der Industrie und dem Do-it-yourself-Bereich, waren zu der Veranstaltung geladen.

Das Kernstück des Jubiläumsevents bildete die hausinterne Ausstellung zu den verschiedenen Produktund Themenbereichen, darunter Lacke und Lasuren, Innen- und Fassadenfarben sowie Industrielacke. Zum Jubiläum erhielten die Besucher zusätzlich einen Einblick in Produktion und Technik. Während der Werksbesichtigung konnten die Besucher die einzelnen Abläufe in den Bereichen Forschung und Entwicklung, Produktion, Warenverteilzentrum und Verwaltung kennenlernen.

\section{Neuer Standort in Planung}

„Wir sind stolz, dass wir das Jubiläum als erfolgreiches Familienunternehmen

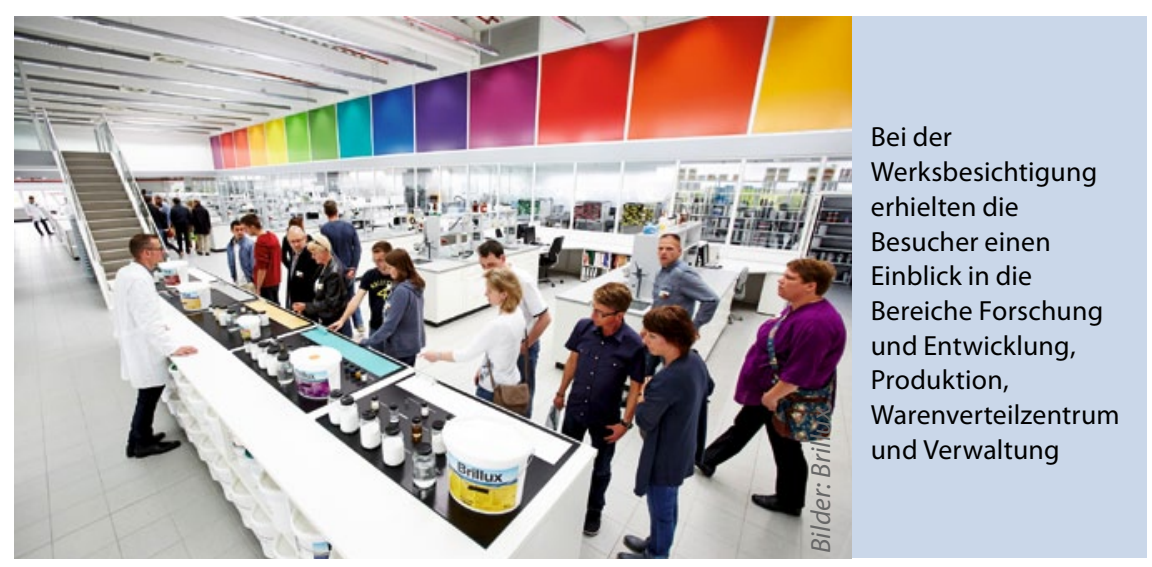

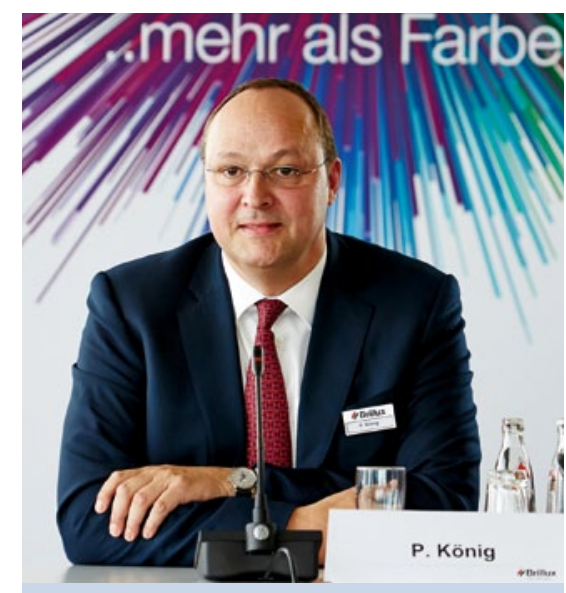

Peter König, Inhaber von Brillux, bei der Eröffnungspressekonferenz am Standort Münster

feiern können,“ so Peter König, Inhaber von Brillux, zu Beginn der Eröffnungskonferenz. Das Unternehmen sei bestens aufgestellt und befinde sich auf Expansionskurs. Seit der Gründung des Unternehmens Hobrecker \& König im Jahr 1889 ist Brillux stetig gewachsen und hat sich zu einem führenden Vollsortimenter und Direktanbieter im Farben- und Lackbereich entwickelt. Dabei wurde ein breites Vertriebsnetz aufgebaut, das heute mehr als 